\title{
DESIGN OF PORTABLE RHEOMETER WITH NEW VANE GEOMETRY TO ESTIMATE CONCRETE RHEOLOGICAL PARAMETERS
}

\author{
Hamza SOUALHI ${ }^{\mathrm{a}}$, El-Hadj KADRI ${ }^{\mathrm{a}}$, Tien-Tung NGO ${ }^{\mathrm{a}}$, Adrien BOUVET ${ }^{\mathrm{a}}$, \\ François CUSSIGH ${ }^{\mathrm{b}}$, Zine-El-Abidine TAHAR ${ }^{\mathrm{a}}$ \\ ${ }^{a}$ Laboratory for Mechanics and Materials in Civil Engineering, Cergy-Pontoise University, \\ 8 Mail Gay Lussac 95000 Neuville sur Oise, France \\ ${ }^{b}$ VINCI Construction, 61, avenue Jules-Quentin, 92730 Nanterre, France
}

Received 15 May 2015; accepted 08 Aug 2015

\begin{abstract}
This paper presents the development of a portable vane rheometer to estimate concrete plastic viscosity and yield stress. The apparatus can be used not only in laboratory but also on construction site. In this study, new blade geometry was proposed to minimize the effect of segregation of concrete during testing, and also to expand the wide range of concrete workability with a slump of approximately from $7 \mathrm{~cm}$ to fluid concrete, and concrete with high plastic viscosity such as concrete with mineral additions. The used blade (U shaped and reversed) allows reducing the vibration of the apparatus, and obtaining more stable measurements. The obtained results permit validating the rheometer test procedure and confirmed that the results are reliable, with a low coefficient of variation of $9 \%$ for repetitive test and of $5.8 \%$ for reproductive tests.
\end{abstract}

Keywords: vane rheometer, concrete, rheology, plastic viscosity, yield stress.

\section{Introduction}

With the development of new concretes such as selfcompacting concrete (SCC), high performance concrete (HPC), and environmental friendly concretes, the control of rheological parameters (yield stress, plastic viscosity) in order to optimize the implementation of these concretes becomes crucial (Wallevik 2006; Wallevik et al. 2015). It is therefore necessary to develop new methods of characterization of the rheological parameters not only in the laboratory but also on construction site.

Empirical tests such as slump and L-Box allow the measurement of these materials but provide little or no information about their viscosity or their behavior under shearing. In this context, rheometers adapted to these fluids have been developed: ICAR (Koehler, Fowler 2004; Koehler et al. 2006); Two points test (Banfill 2011); IBB (Lacombe et al. 1999; Hu, Wang 2010); BML (Faleschini et al. 2014; Wallevik, O. H., Wallevik, J. E. 2011); BTRheom (Hu et al. 1996); MCR (Jau, Yang 2010). These rheometers can differentiate the rheological behavior of different concretes (Banfill et al. 2001; Beaupre et al. 2004; Skripkiūnas, Daukšys 2004).

Recently, two test campaigns were conducted to compare different rheometers (Banfill et al. 2001; Beaupre et al. 2004). The first was performed on 12 low-workability and plastic concretes with rolled or crushed aggregate and fillers, and the second campaign on 16 concretes including a majority of self-compacting concretes mixes. The results of the first campaign are reported in Figure 1. The results of the second campaign are similar to those of the first one.

These studies conclude that the parameters identified by each unit cannot be considered as intrinsic because values vary in significant proportions depending upon the equipment. However, these studies confirm the Bingham behavior of these fresh concretes (Wu, Liu 2015; Wallevik et al. 2015; Yahia, Tanimura 2015; Vance et al. 2015; Faleschini et al. 2014; Choi 2014; Kong et al.

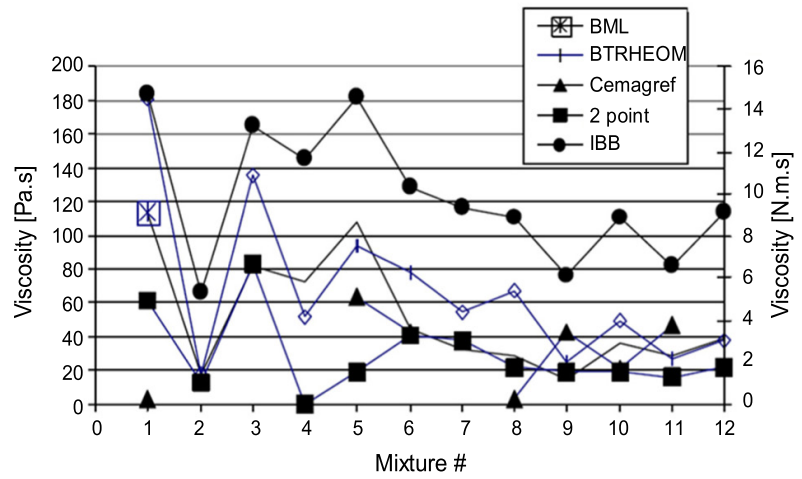

Fig. 1. Values of rheological parameters $(\mathrm{K}$ and $\mu)$ identified on the 12 concretes studied by (Banfill et al. 2001) with different devices 
2013; Banfill 2011; Ngo et al. 2011; Wallevik, O. H., Wallevik, J. E. 2011; Hu, Wang 2010; Gołaszewski 2009; Estellé et al. 2008; Beaupre et al. 2004; Golaszewski, Szwabowski 2003; De Larrard, Sedran 2002; Lacombe et al. 1999; Banfill 1994; Tattersall 1990) which can be described as follows:

$$
\tau=\tau_{0}+\mu \dot{\gamma},
$$

where: $\tau(\mathrm{Pa})$ is the shear stress; $\tau_{0}(\mathrm{~Pa})$ is the yield stress; $\mu$ (Pa.s) is the plastic viscosity and $\dot{\gamma}(1 / \mathrm{s})$ is the shear rate.

Based on existing concrete rheometers, the objective of this work is to develop a portable rheometer adapted to fresh concrete, with a relevant test protocol providing accurate and inexpensive rheological measurements (this test is easy and it can be done without expensive equipment). New blade geometry was used to minimize the effect of segregation of concrete during testing, and also to expand a wide range of concrete workability. This device should be applicable on construction site and in the laboratory in order to meet the demand of the industry (to have a reliable device to accurately measure the high viscosity of concrete with mineral addition). It must be capable of measuring a flow curve or performing a stress growth test and should be appropriate for a wide range of concrete workability with a slump of approximately from $7 \mathrm{~cm}$ to fluid concrete, and concretes with important plastic viscosity such as concrete with mineral additions.

\section{Developed rheometer}

\subsection{Final configuration of rheometer and test procedure}

\subsubsection{Principle of functioning of the rheometer}

The principle is to rotate at different speeds a vane in the form of cross in a cylindrical sample of fresh concrete and measuring the torques exerted to maintain rotation.

A rheological test is performed by imposing a decreasing rotational speed to the vane interrupted by a stabilization stage to perform the measurements. Every second, the control software of the stirrer saves the torque $(M)$ corresponding to the imposed rotation speed $(\Omega)$.

\subsubsection{Description of the apparatus}

The final version of the rheometer is composed of three main parts (Fig. 2): an agitator with speed electronic control for recording the torques via an RS232; a container and a steel vane.

The agitator: The agitator is the key element for the tests. It is attached to an arm, via a jaw, which is itself fixed on a tripod. The agitator is driven by a computer using software (watch \& control) (Fig. 2).

The container: The container is a cylinder of $30 \mathrm{~cm}$ diameter and $25 \mathrm{~cm}$ high. To optimize the adhesion of concrete and to prevent the sliding of concrete on the outer wall of the container, steel rods were welded (Fig. 2).

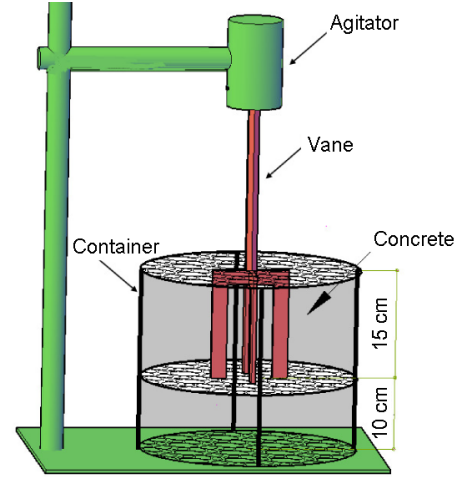

Fig. 2. Rheometer components

The Vane: In the chuck of the agitator, a blade in form of a perpendicular double $U$ is fixed. The blade has a height of $15 \mathrm{~cm}$ and a diameter of $10.5 \mathrm{~cm}$ (Fig. 2).

\subsubsection{Final test procedure}

The measurements are performed with the velocity profile defined in Figure 3 (P48).

Step 1: Filling concrete into the container. It is done by three layers. Each layer receives 25 strokes of stitching using a rod.

Step 2: Positioning of the blade. The blade is centered and thrust into the concrete until the surface of concrete and leaving a layer of concrete of $10 \mathrm{~cm}$ thick below the blade.

Step 3: Measuring torques (M). They correspond to torques to be imposed to maintain speeds in phase bearing when the container is filled with concrete.

Step 4: Using the measurements and calculation of rheological parameters (see next section).

In the next section, the development's step of the apparatus which led to the choice of the presented final configuration of rheometer and the test procedure are detailed.

\subsubsection{Exploitation of the results}

The exploitation of the measurements is to determine the rheological parameters $\tau_{0}$ and $\mu$ from the obtained mea-

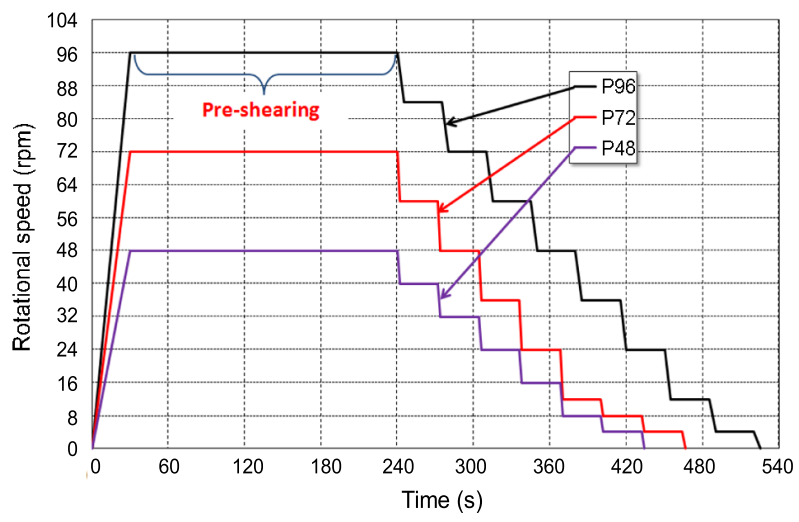

Fig. 3. The tested velocity profiles 
sured torques $\left(M_{i}-\Omega_{i}\right)$. This allows, by assimilating the behavior of concrete at a Bingham fluid (Eqn (1)).

The calculation of the Bingham model parameters of yield stress and plastic viscosity is based on the ReinerRiwlin equation (Eqn (2)):

$$
\Omega=\frac{M}{4 \pi h \mu}\left(\frac{1}{R_{1}^{2}}-\frac{2 \pi h \tau_{0}}{M}\right)-\frac{\tau_{0}}{2 \mu} \ln \frac{M}{2 \pi h \tau_{0} R_{1}^{2}},
$$

where: $\Omega$ - rotational speed ( $\mathrm{rad} / \mathrm{sec}) ; M$ - torque (N.m); $h$ - vane height (m); $R_{1}$ - vane radius (m); $\mu$ - plastic viscosity (Pa.s); $\tau_{0}-$ yield stress $(\mathrm{Pa})$.

The Eqn (2) can be solved with a non-linear optimization. The calculation begins with the supposition of the plastic viscosity and yield stress values. For each measured speed-torque point from the test data, the radius at which flow ceases is calculated based on Eqn (2) using the guessed values of $\tau_{0}$ and $\mu$. For each point, the "calculated rotational speed" is calculated by Eqn (2). The mean squared error (Eqn (3)) is calculated for all points as the difference between the "calculated rotational speed" and the "measured rotational speed":

$$
\text { mse }=\frac{\sqrt{\left(\Omega_{\text {calculated }}-\Omega_{\text {mesured }}\right)^{2}}}{n},
$$

where $n$ is the number of points.

The rheological parameters $\left(\tau_{0}\right.$ and $\mu$ ) are determinate by minimization of the value of $m s e$ with two criteria: $\mu>0$ and $\tau_{0}>0$.

\section{Materials and experimental programme}

Several aggregate sizes within the range of $6 \mathrm{~mm}$ to $20 \mathrm{~mm}$ were used, and the sand size ranged between $0 \mathrm{~mm}$ and $4 \mathrm{~mm}$. The aggregates and sand specific gravity is 2.5. Ordinary Portland cement CEM I 52.5 was used for all the mixtures. The mineral additions used are limestone powder, finely blast furnace slag and fly ash. A polycarboxylic-based superplasticizer (SP) was used in all mixtures with a specific gravity of 1.05 , a solid content of $30 \%$ and a $\mathrm{pH}$ of 7 .

Two series of experimental tests were investigated (Table 1). The first programme (series 1) was used to develop the apparatus and to define the final configuration. The second one (series 2) was used to validate the apparatus (repeatability and reproducibility tests).

\section{Development steps of the rheometer}

\subsection{Choice of velocity profile}

In this step, a cylindrical container of $30 \mathrm{~cm}$ of diameter and $32.5 \mathrm{~cm}$ of height was used with a full blade in dimension $d \times h=10.5 \times 12.5 \mathrm{~cm}$.

To choose a velocity profile in order to have the most stables measurements, many velocity profiles were tested with three reference concretes (B1, B2 and B3) with compositions as given in Table 1 (series 1).

Based on previous studies (Hu et al. 1996; Banfill et al. 2001; Estellé, Lanos 2012; Koehler, Fowler 2004), three rotation rate profiles were tested with three different maximum speeds: the P96 profile with a maximum speed of $96 \mathrm{rpm}$, the P72 profile with a maximum speed of $72 \mathrm{rpm}$ and the $\mathrm{P} 48$ profile with a maximum speed of $48 \mathrm{rpm}$.

At the beginning of the test, the maximum speed is applied pre-shear phase to eliminate the influence of thixotropy (Hafid et al. 2015; Hu et al. 1996). The tested profiles are presented in Figure 3.

The obtained measurements corresponding to the tested profiles are presented in Figures 4 to 6 . The results show that:

- For the three tested concretes, whatever the velocity profile, the necessary time of pre-shearing increases

\begin{tabular}{|c|c|c|c|c|c|c|c|c|c|c|c|c|}
\hline & Name & $\begin{array}{c}V_{\text {paste }} \\
\left(\mathrm{m}^{3}\right)\end{array}$ & $\mathrm{W} / \mathrm{C}$ & $\begin{array}{l}\text { Cement } \\
\left(\mathrm{kg} / \mathrm{m}^{3}\right)\end{array}$ & $\begin{array}{c}\text { Slag } \\
\left(\mathrm{kg} / \mathrm{m}^{3}\right)\end{array}$ & $\begin{array}{l}\text { Fly ash } \\
\left(\mathrm{kg} / \mathrm{m}^{3}\right)\end{array}$ & $\begin{array}{l}\text { Limestone } \\
\left(\mathrm{kg} / \mathrm{m}^{3}\right)\end{array}$ & $\begin{array}{l}\text { SP } \\
(\%)\end{array}$ & $\begin{array}{c}\text { Water } \\
\left(\mathrm{kg} / \mathrm{m}^{3}\right)\end{array}$ & $\begin{array}{c}\text { Aggregate } \\
\left(\mathrm{kg} / \mathrm{m}^{3}\right)\end{array}$ & $\begin{array}{c}\text { Sand } \\
\left(\mathrm{kg} / \mathrm{m}^{3}\right)\end{array}$ & $\begin{array}{l}\text { Slump } \\
(\mathrm{cm})\end{array}$ \\
\hline \multirow{6}{*}{ Series 1} & B1 & \multirow{3}{*}{0.289} & 0.50 & 350 & \multirow{8}{*}{-} & \multirow{8}{*}{-} & \multirow{8}{*}{-} & 0.2 & 175 & 1044 & 815 & 9 \\
\hline & B2 & & 0.40 & 400 & & & & 1.3 & 160 & 1042 & 814 & 20 \\
\hline & B3 & & 0.35 & 430 & & & & 2.0 & 150 & 1041 & 813 & 15 \\
\hline & B4 & 0.370 & \multirow{3}{*}{0.50} & 450 & & & & - & 175 & 923 & 721 & 23 \\
\hline & B5 & $\mathbf{0 . 3 3 0}$ & & 400 & & & & - & 160 & 984 & 768 & 19 \\
\hline & B6 & 0.288 & & 350 & & & & - & 150 & 1044 & 815 & 13 \\
\hline \multirow{5}{*}{ Series 2} & BO 1 & 0.288 & 0.50 & 350 & & & & 0.2 & 175 & 1044 & 815 & 9 \\
\hline & BO 2 & 0.271 & 0.40 & 375 & & & & 1.8 & 150 & 997 & 789 & 18 \\
\hline & BES & \multirow{3}{*}{0.280} & \multirow{3}{*}{0.40} & \multirow{3}{*}{150} & 225 & - & - & \multirow{3}{*}{1.4} & \multirow{3}{*}{150} & \multirow{3}{*}{1054} & \multirow{3}{*}{823} & 17 \\
\hline & BEV & & & & - & 225 & - & & & & & 18 \\
\hline & BEL & & & & - & - & 225 & & & & & 17 \\
\hline
\end{tabular}

Table 1. Concrete mixture compositions 
with increasing of the imposed maximum speed and it is in the order of 2 minutes for a speed of $48 \mathrm{rpm}$;

- The obtained torques for each speed level are stable with the three profiles;

- Segregation was observed at the end of the tests with profiles P96 and P72. It is less important with the profile P48;

- According to the above observations, the profile P48 was retained with a shortening of pre-shearing time at 2 minutes to reduce total time test and decrease the risk of segregation at the end of the test;

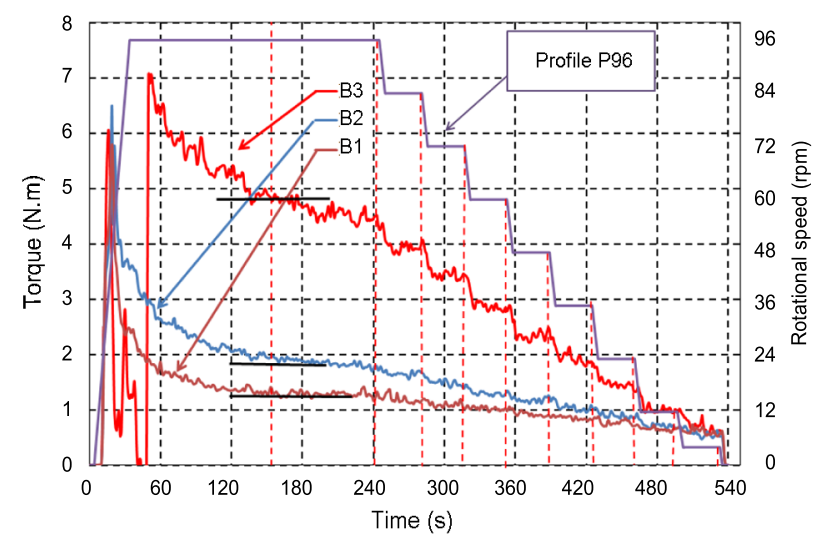

Fig. 4. P96 profile with the three concretes

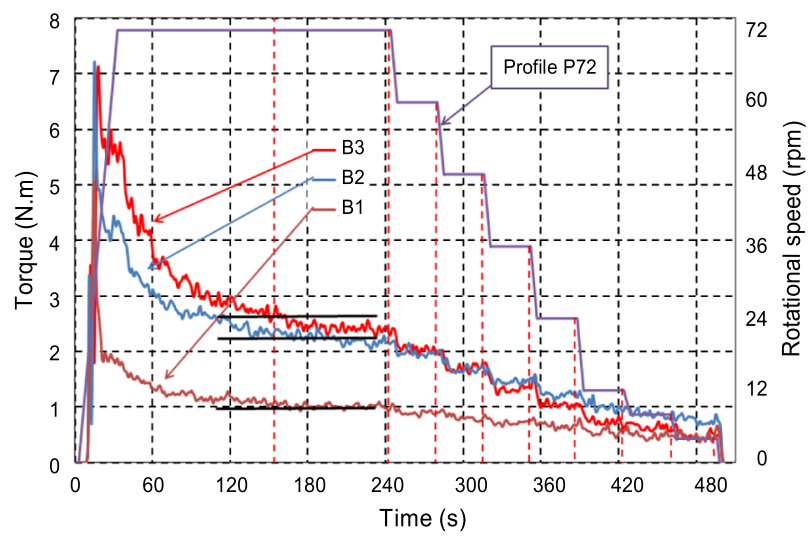

Fig. 5. P72 profile with the three concretes

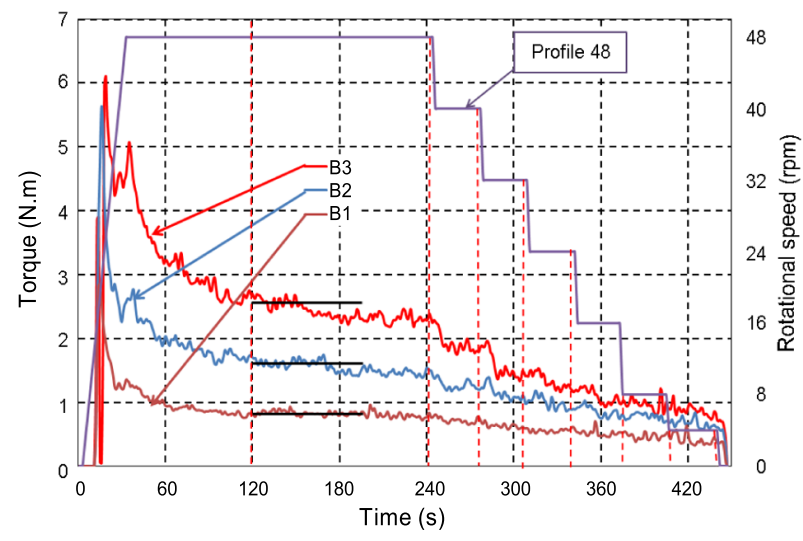

Fig. 6. P48 profile with the three concretes
- For profile P48, the behavior of the three tested concretes can only be better distinguished with the two others profiles.

\subsection{Choice of the container's diameter}

The gap between the blade and the wall of the container may have an influence on the measurements. If it is narrow, it can cause blockages and if it is too large it increases the risk of segregation.

Nguyen and Boger (1985) recommend a ratio between the diameter of the vessel and that of the upper blade 2 and Ferraris (1999) - a gap of the order of five times the maximum diameter of the aggregates $\left(D_{\max }\right)$.

Given these recommendations three cylindrical containers of diameters $D_{1}=25 \mathrm{~cm}, D_{2}=D_{3}=30 \mathrm{~cm}$ and $40 \mathrm{~cm}$ and height were tested. A full blade with dimension $d \times h=10.5 \mathrm{~cm} \times 12.5 \mathrm{~cm}$ was used. The velocity profile retained in the previous step was been used. Three concretes were tested with each container and their compositions are given in the Table 1 (series 1). A fluid concrete (B4), a viscous concrete (B5) and a low-workability concrete (B6).

Figures 7, 8 and 9 represent the torques as a function of the level of rotation speed for the three tested concretes with the three containers. The results show that:

- For the container with diameter $D_{1}$ of $25 \mathrm{~cm}$, measurements are very disturbed especially for viscous

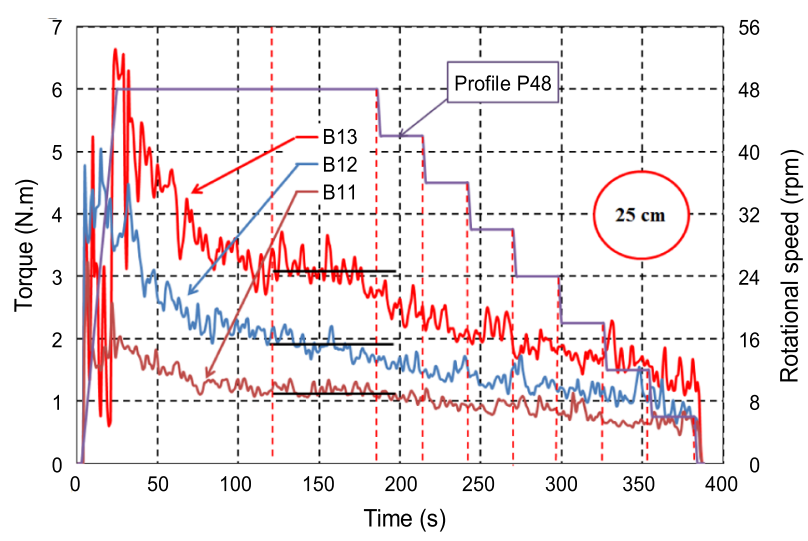

Fig. 7. Results of the container with a diameter of $25 \mathrm{~cm}$

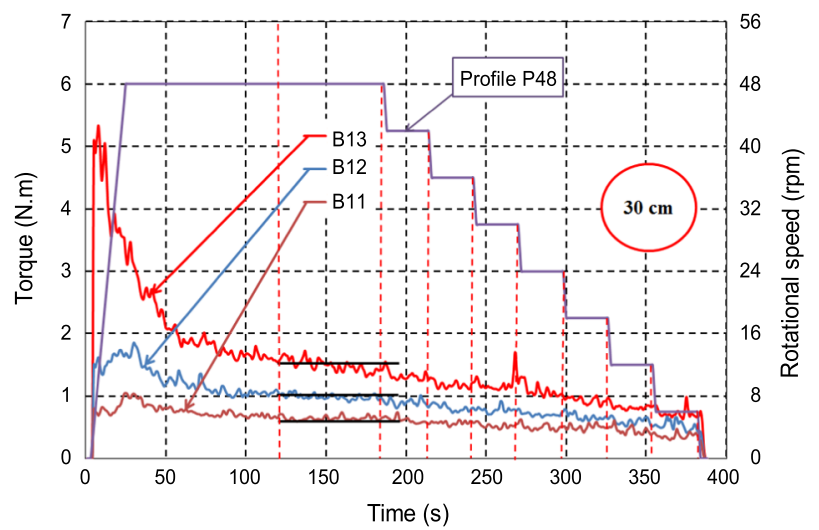

Fig. 8. Results of the container with a diameter of $30 \mathrm{~cm}$ 


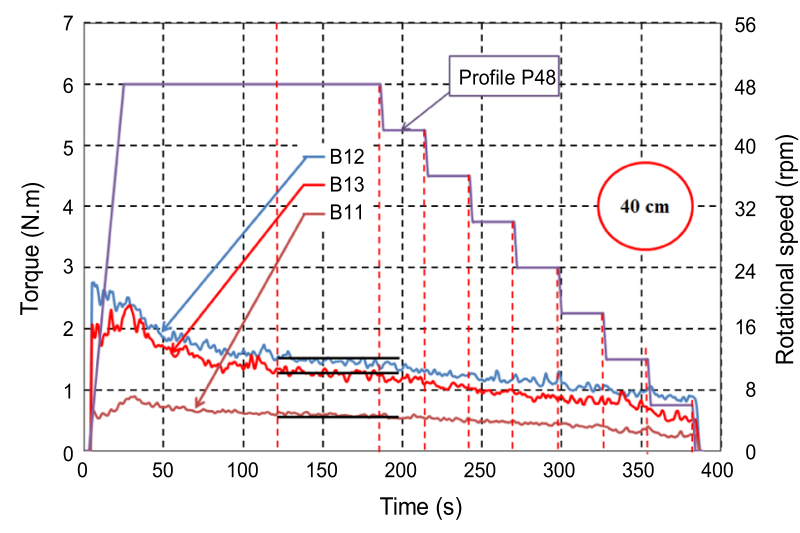

Fig. 9. Results of the container with a diameter of $40 \mathrm{~cm}$

concrete (B5) and the less workable concrete (B6). In addition, blockage and vibration of the apparatus are found during the test due to the narrow air gap.

- For the container with diameter $D_{2}$ of $30 \mathrm{~cm}$, measurements corresponding to each speed are stable with the three tested concretes, and we can clearly distinguish between torques for each level. In addition, the test is more stable (no blocking or vibration) than with $D_{1}$.

- For the container with diameter $D_{3}$ of $40 \mathrm{~cm}$, measurements are also stable, but, we cannot distinguish the difference of torques corresponding to different levels of speed. This can be explained by horizontal segregation due to the considerable width of the air gap. This segregation was confirmed by observations at the end of tests with the three concretes.

These results led us to choose the container with diameter $D_{2}$ of $30 \mathrm{~cm}$ for the final configuration of the rheometer.

\subsection{Influence of the geometry of the blade}

The calculation of the shear stress is made by considering only the lateral friction, i.e. where the shear rate is constant for a given rotational speed. However, the full blade generates considerable friction at its upper and lower faces. Moreover, segregation was observed at the end of many tests with the full blade. It therefore appears clear that the geometry of the blade has a strong influence on the results.

To reduce disturbance measures, for example, Yahia et al. (2006) used the MK-III rheometer Tattersal with a recessed blade (they have an opening on each blade of the blade) (Yahia, Khayat 2006; Yahia et al. 2006).

Thus, to improve the accuracy of measurements and reduce segregation, a study of the geometry of the blade was conducted.

In this study, three blades of the same dimensions $(d \times h=10.5 \mathrm{~cm} \times 12.5 \mathrm{~cm})$, but with different geometries, were tested: a full blade, a hollow blade and a blade in double U shaped and reversed (Fig. 10).

In order to check the concrete condition at the end of the test, a level speed of $48 \mathrm{rpm}$ was added in the imposed velocity profile (P48) after a minute rest after the end of the test. A comparison between the measured average torque at the end of pre-shear (when torques are stabilized) and those measured with the added level (48 rpm) was made.

The results presented in Figures 11 to 13, show that:

- The blade in double U allows having smaller torques according to each level speed in comparison with the other two blades for the three concrete. Lateral friction being identical on the three blades, the blade of a double $\mathrm{U}$ shape therefore reduces the friction on the upper and lower faces. This allows extending the range of concrete to be tested taking into account the maximum power of the agitator.

- Much less vibration was observed during the test with the blade in double $\mathrm{U}$, which allows having more stable measurements. This is because with this shape of blade (similar to the blade of rotary mixer) the aggregates move more freely under shear effect. The comparison between the average torques at the end of the pre-shear level and the average torques according to the added level speed of $48 \mathrm{rpm}$ after the end of the test is summarized in Table 2. The results confirm that, whatever the tested concrete (B1, B2 and B3), the percentage difference $\Delta(\%)$ corresponding to the double

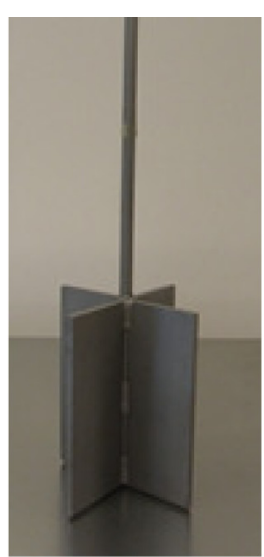

A full blade

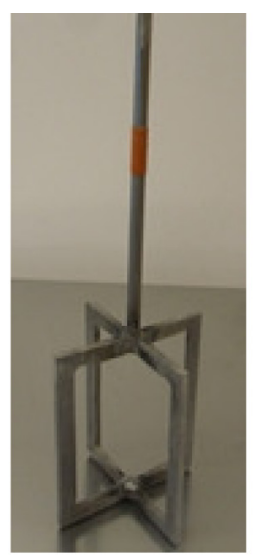

hollow blade

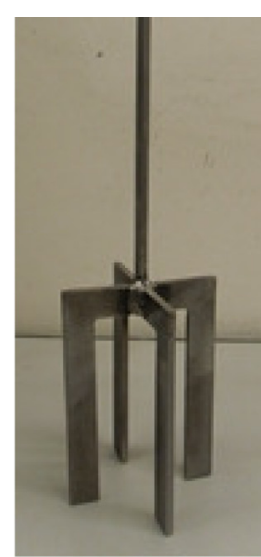

blade in double $\mathrm{U}$
Fig. 10. The three tested blade

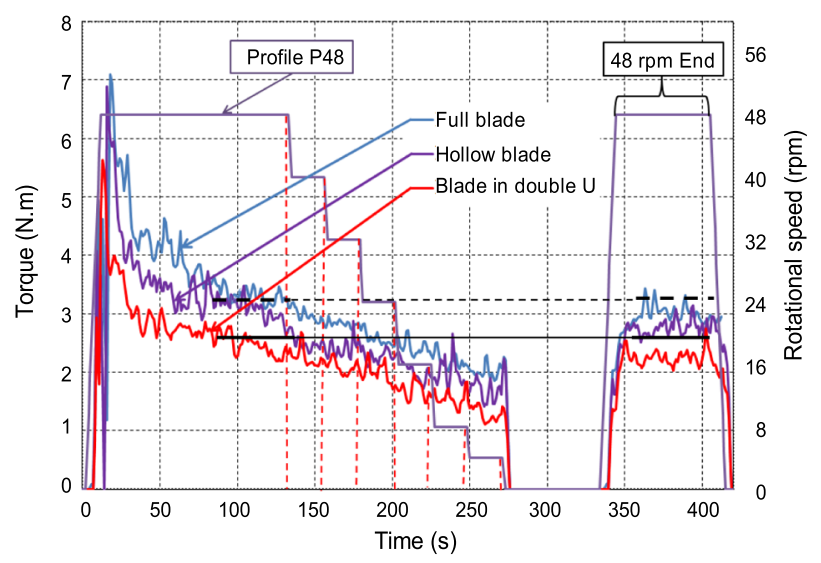

Fig. 11. B1 concrete's measurements with the three blades 


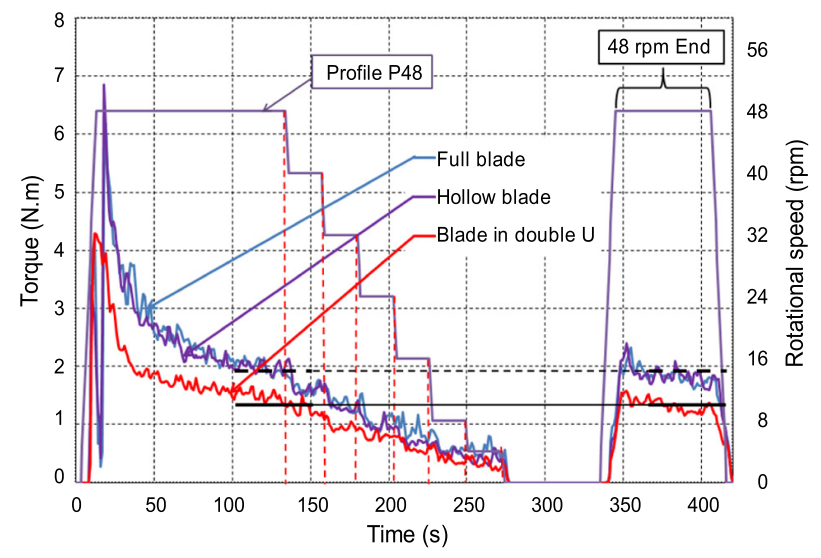

Fig. 12. B2 concrete's measurements with the three blades

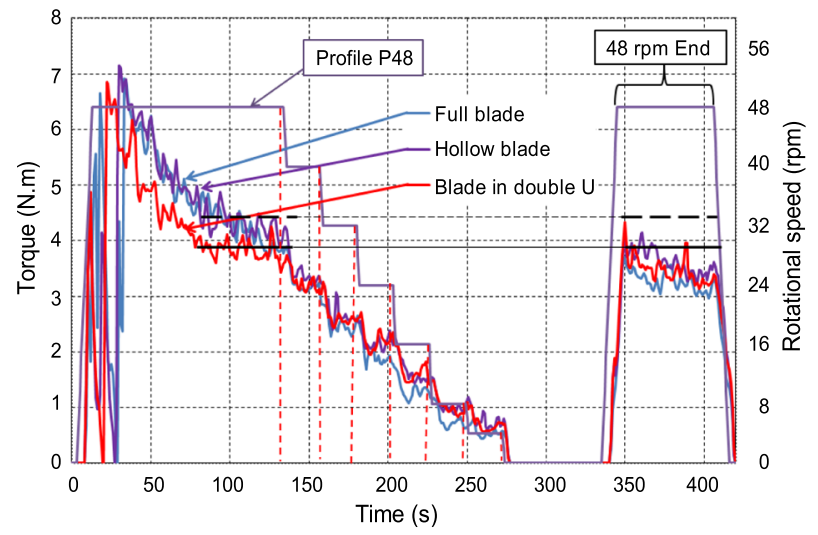

Fig. 13. B3 concrete's measurements with the three blades

U-blade is smaller than that with other blades. It concludes that there is less segregation with the blade in double $\mathrm{U}$. Based on these observations, the blade in double $\mathrm{U}$ was selected for the final configuration of the rheometer.

\section{Validation of the rheometer}

After choosing the final version and defined the procedure of rheometer, tests of repeatability and reproducibility were performed to validate the apparatus. Repeatability tests were used to check if the results obtained from the apparatus are similar for the same concrete Reproducibility tests were used to check if two identical rheometers give similar results for the same concrete.

\subsection{Verification of repeatability of the rheometer}

In order to check the repeatability of the test, three tests were done with similar concretes $\mathrm{BO} 1$ and $\mathrm{BO} 2$ (series 2 in Table 1).

The results presented in Figures 14 and 15 show clearly that the friction torque varies linearly with the speed.

The linear variation of torque- rotational speed curves and the small standard deviation ( $9 \%$ for plastic

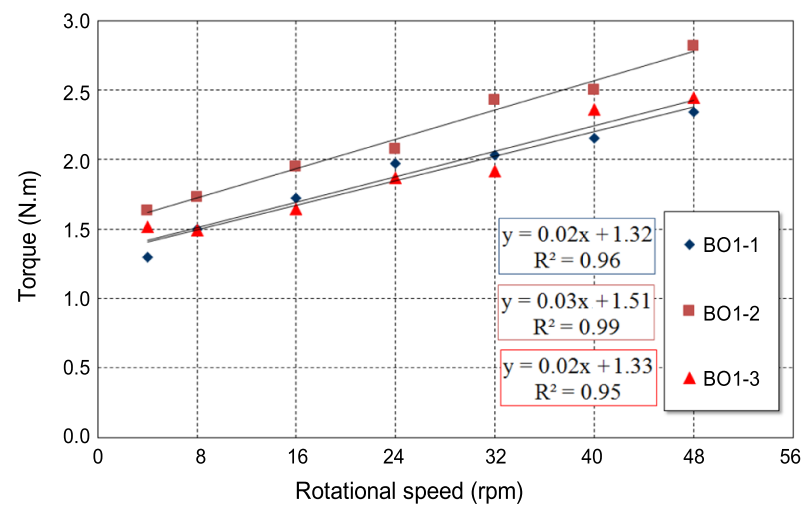

Fig. 14. Variation of torque at different rotational speeds for the repeatability test of the concrete $\mathrm{BO} 1$

Table 2. Comparison between the torques at the beginning and the end of the test

\begin{tabular}{|c|c|c|c|c|}
\hline & Concrete & Full blade & Hollow blade & Blade in double $\mathrm{U}$ \\
\hline \multirow{4}{*}{ B1 } & $48 \mathrm{rpm}$ beginning (N.mm) & 2572 & 3001 & 2404 \\
\hline & $48 \mathrm{rpm}$ end (N.mm) & 2262 & 2796 & 2265 \\
\hline & $\Delta$ (N.mm) & 310 & 204 & 139 \\
\hline & $\Delta(\%)$ & 12.0 & 6.8 & 5.8 \\
\hline \multirow{4}{*}{ B2 } & 48 rpm beginning (N.mm) & 1987 & 1988 & 1491 \\
\hline & $48 \mathrm{rpm}$ end (N.mm) & 1776 & 1809 & 1394 \\
\hline & $\Delta$ (N.mm) & 211 & 179 & 97 \\
\hline & $\Delta(\%)$ & 10.6 & 9.0 & 6.5 \\
\hline \multirow{4}{*}{ B3 } & $48 \mathrm{rpm}$ beginning (N.mm) & 4024 & 4228 & 3801 \\
\hline & $48 \mathrm{rpm}$ end (N.mm) & 3233 & 3469 & 3533 \\
\hline & $\Delta$ (N.mm) & 791 & 759 & 268 \\
\hline & $\Delta(\%)$ & 19.7 & 18.0 & 7.1 \\
\hline
\end{tabular}




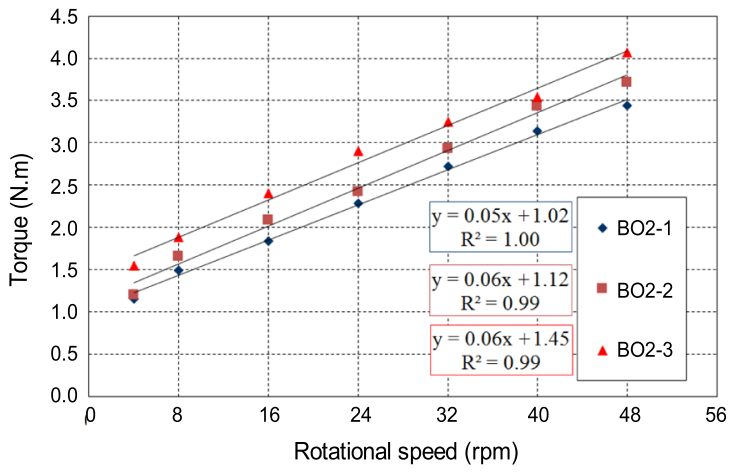

Fig. 15. Variation of torque at different rotational speeds for the repeatability test of the concrete $\mathrm{BO} 2$

Table 3. Variation coefficients of the rheological parameters calculated from the repetitive tests

\begin{tabular}{c|c|c|c|c|c}
\cline { 2 - 5 } & BO1-1 & BO1-2 & BO1-3 & Average & Variation (\%) \\
\hline $\begin{array}{c}\text { Slump } \\
(\mathrm{cm})\end{array}$ & 9 & 10 & 9 & - & - \\
$\begin{array}{c}\mathrm{t}_{0} \\
(\mathrm{~Pa})\end{array}$ & 402 & 554 & 427 & 461 & $\mathbf{1 3 . 5}$ \\
$\begin{array}{c}\mu \\
(\text { Pa.s })\end{array}$ & 23 & 19 & 22 & 21 & $\mathbf{7 . 9}$ \\
\hline
\end{tabular}

\begin{tabular}{c|c|c|c|c|c}
\cline { 2 - 6 } & BO2-1 & BO2-2 & BO2-3 & Average & Variation (\%) \\
\hline $\begin{array}{c}\text { Slump } \\
(\mathrm{cm})\end{array}$ & 18 & 18 & 16 & - & - \\
\hline $\begin{array}{c}\mathrm{t}_{0} \\
(\mathrm{~Pa})\end{array}$ & 248 & 273 & 464 & 328 & $\mathbf{2 7 . 4}$ \\
\hline $\begin{array}{c}\mu \\
(\text { Pa.s })\end{array}$ & 78 & 84 & 63 & 75 & $\mathbf{1 0 . 6}$ \\
\hline
\end{tabular}

viscosity - Table 3) for the obtained rheological parameters proved that the repeatability of the test is good. Hence, it can be concluded that the configuration of the apparatus and the proposed test procedure allows obtaining repeatable results.

\subsection{Verification of the reproducibility of the rheometer}

Two identical rheometers were assembled to test simultaneously different concretes. Each concrete (BES, BEL and BEV) whose compositions are given in the Table 1 (series 2) was tested at the same time on the two apparatus by two different operators. The same procedure was strictly applied for both apparatus.

The obtained results (Fig. 16) show that the curves obtained by the two rheometers are all linear and are very close to each other. In addition, the rheological parameters $\left(\mu, \tau_{0}\right)$ corresponding to each rheometer are obtained with a low coefficient of variation $(5.8 \%$ for viscosity and $3.1 \%$ for yield stress - Table 4 ). Hence, this confirms the reproducibility and also repeatability of the tests.

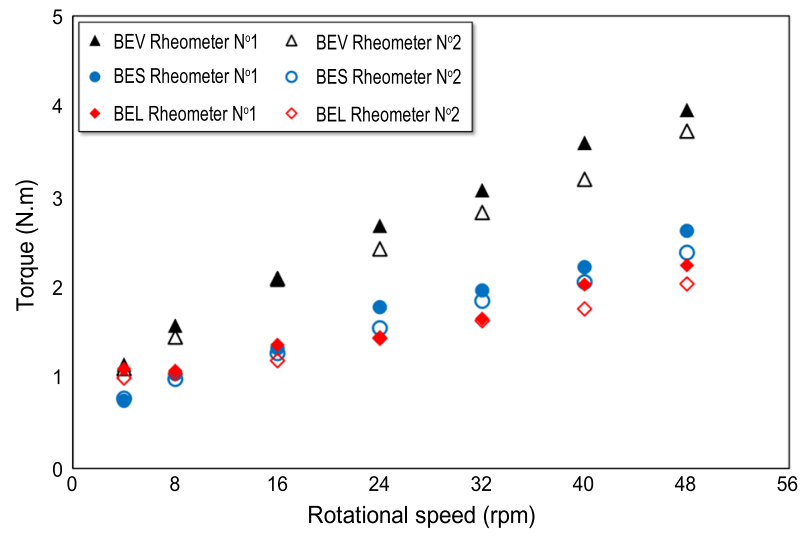

Fig. 16. Evolution of torques with different rotational speed for the concrete during the tests reproducibility on BES concrete, BEV and BEL

Table 4. Variation coefficients of the rheological parameters calculated from the reproducibility tests

\begin{tabular}{c|cccc}
\cline { 2 - 5 } & $\begin{array}{c}\text { BES } \\
\text { Rheometer } \\
1\end{array}$ & $\begin{array}{c}\text { BES } \\
\text { Rheometer } \\
2\end{array}$ & Average & $\begin{array}{c}\text { Variation } \\
(\%)\end{array}$ \\
\hline $\mathrm{t}_{0}(\mathrm{~Pa})$ & 196 & 205 & 201 & 2.2 \\
$\mu($ Pa.s $)$ & 80 & 67 & 73 & 8.9 \\
\hline
\end{tabular}

\begin{tabular}{c|cccc}
\cline { 2 - 5 } & $\begin{array}{c}\text { BEV } \\
\text { Rheometer } \\
1\end{array}$ & $\begin{array}{c}\text { BEV } \\
\text { Rheometer } \\
2\end{array}$ & Average & $\begin{array}{c}\text { Variation } \\
(\%)\end{array}$ \\
\hline $\mathrm{t}_{0}(\mathrm{~Pa})$ & 238 & 239 & 238 & 0.2 \\
$\mu($ Pa.s $)$ & 100 & 87 & 94 & 6.9 \\
\hline \multicolumn{5}{c}{} \\
\cline { 2 - 5 } & $\begin{array}{c}\text { BEL } \\
\text { Rheometer } \\
1\end{array}$ & $\begin{array}{c}\text { ReL } \\
\text { Rheometer }\end{array}$ & Average & $\begin{array}{c}\text { Variation } \\
(\%)\end{array}$ \\
\hline $\mathrm{t}_{0}(\mathrm{~Pa})$ & 266 & 231 & 249 & 7.0 \\
$\mu($ Pa.s $)$ & 32 & 31 & 31 & 1.6 \\
\hline
\end{tabular}

\section{Conclusions}

A rheometer was developed to meet the industrial needs for a reliable device that measures the rheological parameters of fluid concrete with good accuracy and high stability.

The developed rheometer has the same operating principle of the ICAR device and Estellés et al. (2008) rheometer, the difference being the geometry of blade and the speed profile. This apparatus is designed for mobile use on site and in laboratories at a low cost.

The used blade ( $U$ shaped and reversed) reduces the vibration of the apparatus, and obtain more stable measurements, to minimize the segregation of the concretes during the test and to expand the wide range of concrete workability from a slump of approximately $7 \mathrm{~cm}$ and concretes with important plastic viscosity such as concretes with mineral addition to fluid concrete. 
Rheometer measurements are repetitive with a low coefficient of variation $(9 \%)$ When the same parameters are measured by two identical concrete rheometers, piloted by two different operators, the tests are reproductive with a low coefficient of variation $(5.8 \%)$.

Measurements obtained from the rheometer tests allow distinguishing clearly the rheological parameters of different concretes.

\section{References}

Banfill, P.; Beaupre, D.; Chapdelaine, F.; De Larrard, F.; Domone, P.; Nachbaur, L., et al. 2001. Comparison of concrete rheometers: international tests at LCPC (Nantes, France), in C. F. Ferraris, L. E. Brower (Eds.). NISTIR 6819. National Institute of Standards and Technology, USA.

Banfill, P. F. G. 1994. Rheological methods for assessing the flow properties of mortar and related materials, Construction and Building Materials 8(1): 43-50.

https://doi.org/10.1016/0950-0618(94)90007-8

Banfill, P. F. G. 2011. Additivity effects in the rheology of fresh concrete containing water-reducing admixtures, Construction and Building Materials 25(6): 2955-2960. https://doi.org/10.1016/j.conbuildmat.2010.12.001

Beaupre, D.; Chapdelaine, F.; Domone, P.; Koehler, E.; Shen, L.; Sonebi, M., et al. 2004. Comparison of concrete rheometers: international tests at $\mathrm{MB}$, in C. F. Ferraris, L. E. Brower (Eds.). NISTIR 7154. National Institute of Standards and Technology, USA.

Choi, M. 2014. Numerical prediction on the effects of the coarse aggregate size to the pipe flow of pumped concrete, Journal of Advanced Concrete Technology 12(8): 239-249. https://doi.org/10.3151/jact.12.239

De Larrard, F.; Sedran, T. 2002. Mixture-proportionning of high-performance concrete, Cement and Concrete Research 31(11): 1699-1704.

https://doi.org/10.1016/S0008-8846(02)00861-X

Estellé, P.; Lanos, C. 2012. High torque vane rheometer for concrete: principle and validation from rheological measurements, Applied Rheology 22(1): 12881-12888.

Estellé, P.; Lanos, C.; Perrot, A. 2008. Processing the couette viscometry data using a Bingham approximation in shear rate calculation, Journal of Non Newtonian Fluid Mechanics 154(1): 31-38. https://doi.org/10.1016/j.jnnfm.2008.01.006

Faleschini, F.; Jiménez, C.; Barra, M.; Aponte, D.; Vázquez, E.; Pellegrino, C. 2014. Rheology of fresh concretes with recycled aggregates, Construction and Building Materials 73: 407-416. https://doi.org/10.1016/j.conbuildmat.2014.09.068

Ferraris, C. F. 1999. Measurement of the rheological properties of high performance concrete: state of the art report, Journal of Research of the National Institute of Standards and Technology 104(5): 461-478.

https://doi.org/10.6028/jres.104.028

Gołaszewski, J. 2009. Influence of viscosity enhancing agent on rheology and compressive strength of superplasticized mortars, Journal of Civil Engineering and Management 15(2): 181-188.

https://doi.org/10.3846/1392-3730.2009.15.181-188

Golaszewski, J.; Szwabowski, J. 2003. Influence of superplasticizer on rheological behaviour of fresh cement mortars, Cement and Concrete Research 34(2): 235-248. https://doi.org/10.1016/j.cemconres.2003.07.002

Hafid, H.; Ovarlez, G.; Toussaint, F.; Jezequel, P. H.; Roussel, N. 2015. Assessment of potential concrete and mor- tar rheometry artifacts using magnetic resonance imaging, Cement and Concrete Research 71: 29-35.

https://doi.org/10.1016/j.cemconres.2015.01.009

Hu, C.; De Larrard, F.; Sedran, T.; Boulay, C.; Bosc, F.; Deflorenne, F. 1996. Validation of BTrheom the new rheometer for soft-to-fluid concrete, Materials and Structures 29(10): 620-631. https://doi.org/10.1007/BF02485970

Hu, J.; Wang, K. 2010. Effect of coarse aggregate characteristics on concrete rheology, Construction and Building Materials 25(3): 1196-1204. https://doi.org/10.1016/j.conbuildmat.2010.09.035

Jau, W. C.; Yang, C. T. 2010. Development of a modified concrete rheometer to measure the rheological behavior of conventional and self-consolidating concretes, Cement and Concrete Composites 32(6): 450-460. https://doi.org/10.1016/j.cemconcomp.2010.01.001

Koehler, E. P.; Fowler, D. W. 2004. Development of a portable rheometer for fresh Portland cement concrete. ICAR Report 105-3F. Aggregates Foundation for Technology, Research and Education.

Koehler, E. P.; Fowler, D. W.; Ferraris, C. F.; Amziane, S. 2006. New portable rheometer for fresh self-consolidating concrete, ACI Materials Journal 233(7): 97-116.

Kong, X.; Zhang, Y.; Hou, S. 2013. Study on the rheological properties of Portland cement pastes with polycarboxylate superplasticizers, Rheologica Acta 52(7):707-718. https://doi.org/10.1007/s00397-013-0713-7

Lacombe, P.; Beaupre, D.; Pouliot, N. 1999. Rheology and bonding characteristics of self-levelling concrete as a repair material, Materials and Structures 32(8): 593-600. https://doi.org/10.1007/BF02480494

Ngo, T. T.; Kadri, E. H.; Cussigh, F.; Bennacer, R. 2011. Measurement and modelling of fresh concrete viscous constant to predict pumping pressure, Canadian Journal of Civil Engineering 38(8): 944-956.

https://doi.org/10.1139/111-058

Nguyen, Q. D.; Boger, D. V. 1985. Direct yield stress measurement with the vane method, Journal of Rheology 29(3): 335-347. http://dx.doi.org/10.1122/1.549794

Skripkiūnas, G.; Daukšys, M. 2004. Dilatancy of cement slurries with chemical admixtures, Journal of Civil Engineering and Management 10(3): 227-233. https://doi.org/10.1080/13923730.2004.9636310

Tattersall, G. H. 1990. Application of rheological measurements to practical control of concrete, in Proceedings of the International Conference on "Rheology of Fresh Cement and Concrete”, 16-29 March 1990, Liverpool, UK, 270-280.

Vance, K.; Sant, G.; Neithalath, N. 2015. The rheology of cementitious suspensions: a closer look at experimental parameters and property determination using common rheological models, Cement and Concrete Composites 59: $38-48$. https://doi.org/10.1016/j.cemconcomp.2015.03.001

Wallevik, J. E. 2006. Relationship between the Bingham parameters and slump, Cement and Concrete Research 36(7): 1214-1221. https://doi.org/10.1016/j.cemconres.2006.03.001

Wallevik, O. H.; Wallevik, J. E. 2011. Rheology as a tool in concrete science: the use of rheographs and workability boxes, Construction and Building Materials 41(12): 12791288. http://dx.doi.org/10.1016/j.cemconres.2011.01.009

Wallevik, O. H.; Feys, D.; Wallevik, J. E.; Khayat, K. H. 2015. Assessment of potential concrete and mortar rheometry artifacts using magnetic resonance imaging, Cement and Concrete Research 71: 29-35. https://doi.org/10.1016/j.cemconres.2015.01.009 
Wu, Y. H; Liu, K. F. 2015. Formulas for calibration of rheological parameters of Bingham fuid in Couette Rheometer, Journal of Fluids Engineering 137(4): 041202-041213. https://doi.org/10.1115/1.4028813

Yahia, A.; Khayat K. H. 2006. Modification of the concrete rheometer to determine rheological properties of self-consolidating concrete - van device, in the $2^{\text {nd }}$ International RILEM Symposium on Advances in Concrete through Science and Engineering, 11-13 September 2006, Quebec, Canada.
Yahia, A.; Khayat K. H.; Sayed, M. 2006. Statistical design to evaluate the coupled effect of mixture parameters and rebar spacing on flow characteristics of SCC, in the $2^{\text {nd }} I n$ ternational RILEM Symposium on Advances in Concrete through Science and Engineering, 11-13 September 2006, Quebec, Canada.

Yahia, A.; Tanimura, M. 2015. Rheology of belite-cement effect of w/c and high-range water-reducer type, Construction and Building Materials 88: 169-174. https://doi.org/10.1016/j.conbuildmat.2015.03.029

Hamza SOUALHI. PhD in Civil Engineering, Associate Professor at Civil Engineering Department, University of Cergy-Pontoise, France. Member at the Laboratory for Mechanics and Materials in Civil Engineering (L2MGC). His main research interests: new materials, methods of mix-design of concrete, special concretes (HPC, SCC and Eco-friendly concrete), rheology, tribology, and pumping of concrete.

EI-Hadj KADRI. Professor at Civil Engineering Department, University of Cergy-Pontoise, France. Assistant Director of Laboratory for Mechanics and Materials in Civil Engineering. His main research interests: new materials, methods of mix-design of concrete, special concretes (HPC, SCC and Eco-friendly concrete), rheology, tribology, and pumping of concrete.

Tien-Tung NGO. PhD in Civil Engineering, Associate Professor at Civil Engineering Department, University of Cergy-Pontoise, France. Member at the Laboratory for Mechanics and Materials in Civil Engineering (L2MGC). His main research interests include rheology, tribology, and pumping of concrete (SCC and Eco-friendly concrete).

Adrien BOUVET. PhD in Civil Engineering, Associate Professor at Civil Engineering Institute, University of Cergy-Pontoise, France. Member at the Laboratory for Mechanics and Materials in Civil Engineering (L2MGC). His main research interests include rheology, tribology of concrete (SCC and Eco-friendly concrete), and thermal properties of materials.

François CUSSIGH. Expert on concrete in Vinci Construction France. His main research interests: new materials, methods of mixdesign of concrete, special concretes (HPC, UHPC, SCC and Eco-friendly concrete), rheology tribology, and pumping of concrete.

Zine-El-Abidine TAHAR. PhD student in the Laboratory for Mechanics and Materials in Civil Engineering, University of CergyPontoise. 